\title{
CRÍTICA À LÓGICA RACIONALISTA EM “A TERCEIRA MARGEM DO RIO”, DE GUIMARÃES ROSA
}

\section{CRITICS TO THE RATIONALIST LOGIC "IN THE THIRD BANK OF THE RIVER" BY GUIMARÃES ROSA}

Bruno José Bezerra Ribeiro ${ }^{l}$

(brunojbr10@hotmail.com)

Fabrício Lemos da Costa ${ }^{2}$

(fabricio.lemos1987@yahoo.com.br)

\begin{abstract}
RESUMO
Este ensaio tem como objetivo refletir sobre a crítica à lógica racionalista no conto "A terceira margem do rio", de Guimarães Rosa, constituindo-se em uma problematização da realidade ficcional das narrativas latino-americanas do século XX, cuja máxima encontra-se no conflito que se instala no velho pensamento dialético herdado, sobretudo, de Aristóteles. Assim, este trabalho tem como clave a produção moderna, na qual a questão dá-se na relação entre o homem e a perspectiva racional, em que não se pode compreender a realidade pelo viés da velha lógica.
\end{abstract}

Palavras-chave: Lógica; Primeiras Estórias; Sertão; Narrativa Latino-Americana; Século XX.

\section{ABSTRACT}

This essay aims to reflect on the critique to the rationalist logic in Guimarães Rosa's short story "The third bank of the river", constituting a problematization of the fictional reality of the Latin American narratives of the twentieth century, which lies in the conflict that is installed in the old dialectical thinking inherited, above all, from Aristotle. Thus, this work has as a key the modern production, in which the question arises in the relation between man and the rational perspective, on what reality cannot be understood by the bias of the old logic.

Key words: Logic; first stories; backcountry; Latin-American narratives; $20^{\text {th }}$ century.

\footnotetext{
${ }^{1}$ Graduado em Filosofia pela Universidade do Estado do Amapá (UEAP).

CV Lattes: http://lattes.cnpq.br/2412733097629070.

${ }^{2}$ Especialista em Produção de Material Didático e Formação de Mediadores de leitura para EJA pela Universidade Federal do Amapá (UNIFAP).

CV Lattes: http://lattes.cnpq.br/0033871728934155.
} 
O livro Primeiras Estórias, coletânea de vinte e um contos publicada em 1962 pela Editora Livraria José Olympio, apresenta uma diversidade de acontecimentos no sertão dos Gerais cuja intensidade se dá sobretudo a partir da violência na relação entre grupos de sertanejos que lutam, perseguem e fogem na amargura do sertão. Entretanto, ao lado do panorama dos conflitos pelo poder, um conto destaca-se pela dimensão de um sertão que coloca o homem em uma perspectiva ontológica ${ }^{3}$. A narrativa apresenta-se numa outra margem, "A terceira margem do rio", título que instaura no texto um viés para fora do panorama dialético do racionalismo lógico.

Em "A terceira margem do rio", os acontecimentos desenvolvem-se a partir da escolha de um velho sertanejo de construir uma canoa, sem aviso prévio ou qualquer justificativa. $\mathrm{O}$ personagem passa a habitá-la ${ }^{4}$, entre uma margem e outra, não declarando o motivo da nova forma de vida, sobrevivendo no silêncio de um rio que corta a casa, espaço da convivência familiar: "Era a sério. Encomendou a canoa especial, de pau de vinhático, pequena, mal com tabuinha da popa, como para caber justo o remador. Mas teve de ser toda fabricada, escolhida forte e arqueada em rijo, própria para dever durar na água por uns vinte ou trinta anos" (ROSA, 2001, p. 79).

Dessa forma, instala-se um clima de mistério ao longo da narrativa, em que a não revelação do pai é causa de variadas possibilidades, mas nenhuma acertada, porque o silêncio impera desde o momento da despedida. No silêncio, a família espera pelo retorno do patriarca, que nunca voltaria: "Nosso pai não voltou. Ele não tinha ido a nenhuma parte. Só executava a invenção de se permanecer naqueles espaços do rio, de meio a meio, sempre dentro da canoa, para dela não saltar, nunca mais. A estranheza dessa verdade deu para estarrecer de todo a gente. Aquilo que não havia, acontecia" (Ibidem, p. 80, grifo nosso).

\footnotetext{
${ }^{3}$ Benedito Nunes, em $O$ dorso do tigre, sublinha que no sertão ficcional de Guimarães Rosa o sertanejo está imerso no destino que o move a partir de sua trajetória, configurando-se na existência humana daqueles que transitam pela terra, longe da concepção cristã, mas mergulhados no conhecer a si mesmo das longas viagens. De acordo com Nunes: "É essa atividade temporal da existência, fulcro da poiesis originária, que constitui, na obra de Guimarães Rosa, o último horizonte simbólico da viagem. Vê-se, então, que o significado final desse motivo se afasta da ideia cristã do homo viator, segundo a qual o homem apenas transitaria no mundo, que não corresponde nem à sua origem nem ao seu verdadeiro destino. Para Guimarães Rosa, não há, de um lado, o mundo, e, de outro, o homem que o atravessa. Além de viajante, o homem é a viagem - o objeto e sujeito da travessia, em cujo processo o mundo se faz. Ele atravessa a realidade conhecendo-a, e conhece-a mediante a ação da poiesis originária, dessa atividade criadora, que nunca é tão profunda e soberana como no ato de nomeação das coisas, a partir do qual se opera a fundação do ser pela palavra, de que fala Heidegger" (NUNES, 2009, p. 171-172).

${ }^{4}$ Palavra de origem latina, habitare. Aqui, entendemos o termo habitar em seu valor significativo original: permanecer, morar, constituir pensamento, cultura e reflexão em lugar fixo.
} 
Nesse sentido, "A terceira margem do rio" dialoga com a literatura do século XX, com narrativas que representam o boom da produção literária da América Latina, cujo representante no Brasil é João Guimarães Rosa. Nessas produções, a relatividade e o questionamento da lógica racional são colocados em processo de reflexão e dúvida. Segundo Coutinho: "Nesse universo, em que a vida se apresenta como mistério e perplexidade e a relatividade é a única maneira de apreender a realidade, o racionalismo e o senso comum são constantemente postos em xeque" (COUTINHO, 2013, p. 42).

Assim, as narrativas da América Latina do século XX constituem-se em uma espécie de "forma múltipla", nascida da tensão entre os modelos da antiga matriz e a busca de uma identidade nacional. Do jogo de oposição resultou-se uma nova forma, que se institui na negação de tendências tradicionais que se evidenciam numa linha reta, objetiva, isto é, que trazem em seu bojo o modelo de exclusão dos opostos. Por outro lado, a literatura latinoamericana coloca-se como devedora da relatividade, em que nada é central, desenvolvendo-se na pluralidade, como sublinha Coutinho:

A narrativa latino-americana sempre se caracterizou, durante todo o seu desenvolvimento histórico, pela presença de uma tensão entre tendências opostas que se expressavam através de pares antinômicos do tipo: regionalismo $\mathrm{x}$ universalismo, objetivismo x subjetivismo, consciência estética $\mathrm{x}$ engajamento social. Essas tendências, que refletem, num plano mais genérico, a oscilação comum na cultura latino-americana entre a acomodação aos modelos transpostos para o continente pelos colonizadores europeus e a busca de uma identidade nacional, mesclam-se na chamada "nova narrativa", dando lugar a uma espécie de "forma múltipla" ou "plural", que faz coexistirem em seu próprio corpus todos esses elementos tradicionalmente opostos. (Ibidem, p. 52)

A narrativa de Rosa, ao dialogar com a produção latino-americana do século XX, entra em oposição com antigas formas de narrar do realismo literário, assim como com o chamado regionalismo de 30 da literatura brasileira, que tinha como parâmetro a paisagem e seu exotismo, colocando-se como uma espécie de "fotografia" de imagem objetiva. O autor mineiro incorpora na literatura nacional do século XX, então, a problematização do sujeito enquanto formador de pensamento e reflexão, com suas dúvidas e incertezas, as quais são revestidas quase sempre de perguntas sem respostas. De acordo com Coutinho: “Assim, de um lado, há um romance 'regionalista', marcado por uma preocupação com a descrição da terra, do típico, e, de outro, uma espécie de ficção 'universalista', voltada aos conflitos psicológicos e existenciais do homem" (Ibidem, p. 53). 
Betina R. R. da Cunha, em Um tecelão ancestral: Guimarães Rosa e o discurso mítico, no capítulo "Um silencioso discurso mítico: 'a terceira margem do rio"”, afirma que a narrativa caminha para uma desconstrução da lógica ocidental ${ }^{5}$, marcando-se para além da dialética aristotélico-hegeliana e fazendo-se presente no próprio título do conto: “A terceira margem do rio". Assim, o enredo constitui-se no interior do discurso mítico ${ }^{6}$, cujos acontecimentos não se dão na cronologia do tempo histórico. Fala-se, portanto, de valores que ultrapassam a lógica, desenvolvendo-se por meio de paradoxo. De acordo com Cunha:

O paradoxo anuncia-se, no conto rosiano, já a partir do título "A terceira margem do rio", colocando o leitor diante de uma interrogação e uma duvidosa negação, uma vez que ao significado foi acrescido um novo sema referencial ( $3^{\mathrm{a}}$ margem) comprometendo a convencionalidade implícita no significante e, em consequência, destruindo ou alongando o sentido do signo "rio". (CUNHA, 2009, p. 84)

O paradoxo faz parte da conjuntura narrativa da literatura latino-americana do século XX - como sublinhamos anteriormente -, século no qual no Brasil entrou em amadurecimento com o autor mineiro. Em “A Terceira margem do rio”, o paradoxo desconstrói o cerne da lógica racionalista ao instaurar o absurdo no cotidiano dos personagens, como é citado pelo narradorpersonagem nos fragmentos "perto e longe de sua família dele" (ROSA, 2001, p. 80-81), "aquilo que não havia, acontecia" (Ibidem, p. 80), e ainda em "Nosso pai não voltou. Ele não tinha ido a nenhuma parte" (Ibidem, p. 80).

$\mathrm{Na}$ narrativa, portanto, o mundo encontra-se fora da racionalidade, em um lugar inexplicável, ou seja, na ausência de valores dialéticos, em que o centro é a clave do mítico, com suas perguntas, questões abertas que preenchem todo o texto, sobretudo a partir do filho. O menino sofre a ausência, revelando-nos alguns traços do caráter psicológico do pai: "Nosso pai era homem cumpridor, ordeiro, positivo; e sido assim desde mocinho e menino, pelo que testemunharam as diversas sensatas pessoas, quando indaguei a informação" (Ibidem, p. 79).

\footnotetext{
5 "Tal lógica ocidental poderia ser vista como um feixe de notações discursivas (palavras, proposições, pensamentos) que se organiza em função de polaridades, oposições e dialéticas, propondo delimitar, através de demonstrações persuasivas, os espaços e os campos pelos quais o 'provável' ou o 'verdadeiro' poderiam se estruturar e se realizar." (CUNHA, 2009, p. 83)

${ }^{6}$ Eduardo F. Coutinho afirma em Grande Sertão: Veredas. Travessias que o mito se faz necessário em uma produção literária que não se sustenta pela racionalidade - isto é, na nova forma narrativa a relatividade coloca-se como viés que aponta à tensão interna de literaturas latino-americanas, fora do eixo do centro enquanto certeza absoluta. Segundo Coutinho: "Nesse sentido, questiona a todo instante o realismo tradicional em suas obras e insinua frequentemente a viabilidade do mito" (COUTINHO, 2013, p. 30).
} 
Por outro lado, esse narrador, filho afetado pela ida sem resposta, procura entre os conhecidos, entre "as diversas pessoas sensatas" (Ibidem, p. 79), uma pista que o possa fazer compreender o real motivo da empreitada daquele homem; no entanto, a informação recebida pela vizinhança em relação ao pai o deixa mais confuso, porque não se justificava um sujeito "positivo" ir morar numa canoa, espaço mínimo para a sobrevivência de qualquer humano. No silêncio paterno, o narrador rememora o dia em que a canoa ficara pronta:

Nosso pai nada não dizia. Nossa casa, no tempo, ainda era mais próxima do rio, obra de nem quatro de légua: o rio por aí se estendendo grande, fundo, calado que sempre. Largo, de não se poder ver a forma da outra beira. E esquecer não posso, do dia em que a canoa ficou pronta. (Ibidem, p. 80)

Luiz Fernando Valente, em Mundividências: leituras comparativas de Guimarães Rosa, no capítulo "Fabulação e Mediação: A terceira margem do rio e O barão nas árvores", argumenta que não se trata de um viés fantástico ou sobrenatural em "A terceira margem do rio", porque não se encontra em questão uma espécie de hesitação, como formulara Tzvetan Todorov em Introdução à literatura fantástica: "Há um fenômeno estranho que se pode explicitar de duas maneiras, por meio de causas de tipo natural e sobrenatural. A possibilidade de se hesitar entre os dois criou o efeito fantástico" (TODOROV, 2010, p. 31).

Dessa forma, como argumenta Valente, a vida cotidiana daquele pequeno lugarejo não muda em nada; pelo contrário, as pessoas, com exceção do filho mais velho, voltam ao cotidiano. A esposa resolve ir embora com a filha que casara e o outro filho migra para a cidade. Enquanto isso, o filho mais velho sempre está à beira daquele rio, perplexo, sem uma explicação acertada. Portanto, tudo o que sabemos na narrativa são impressões de um narrador demasiadamente angustiado com a incerteza. Segundo Valente:

Esse aspecto é de fundamental importância porque esses textos não recorrem à fantasia como meio de escapar ao mundo, mas como forma de problematizá-lo, não como fuga à realidade, mas como meio de questionar a própria definição de "realidade". (VALENTE, 2011, p. 88)

Assim, o problema da lógica dá-se na ausência da perspectiva dialética, pois a narrativa encontra-se na "margem" não real - e não na dimensão sobrenatural, em que a hesitação é a mola propulsora. Dessa forma, em “A terceira margem do rio", não se trata do caráter dialético, ou seja, da possibilidade de explicações a partir de duas possibilidades. No conto, a terceira margem frustra a racionalidade ocidental, já que não se explica pela polarização dos acontecimentos. Aristóteles argumenta no Órganon: 
Também é preciso escolher argumentos que se relacionem à mesma tese e compará-los, uma vez que este procedimento supre copioso material para constranger o opositor e representa também grande ajuda na refutação, quando se terá uma grande quantidade de argumentos tanto a favor quanto contra, pois o resultado é que nos colocamos em guarda contra os argumentos contrários. Ademais, perceber ou ter percebido de um relance os resultados de cada uma de duas hipóteses não constitui instrumento desprezível para o culto do conhecimento e da sabedoria filosófica, pois então só restará fazer a correta eleição de um dos dois. (ARISTÓTELES, Órganon, VIII, XIV, 163 b5-10, grifo nosso)

Audemaro Taranto Goulart, em "A insatisfação com as margens do rio", afirma que a narrativa é apreciada como um dos contos mais importantes da literatura brasileira, e os críticos empenham-se, desde sua publicação em 1962, na busca pela maneira de melhor interpretar o enredo - o título, inclusive, já se coloca como estranho à dialética ocidental, mesmo em um texto literário: “Tomando a deixa do título, a crítica sentencia que o pai, certamente, foi buscar - e alcançou - a terceira margem do rio. E, nesse ponto, supondo-se imune ao 'decifra-me ou devoro-te"” (GOULART, 2001, p. 7).

"Decifra-me ou devoro-te" dá-se na clave da escolha, na perspectiva lógica da dialética racional ocidental. Em "A terceira margem do rio", por outro lado, a crítica vira uma margem fora do eixo da polaridade, ou seja, naquilo que Goulart desenvolve como "uma nova realidade, a transcendência, o encontro de uma outra vida, a superação dos limites humanos etc. etc. etc." (Ibidem, p. 7). Então, o texto converge, segundo a crítica especializada, em um problema da própria realidade no interior da escolha do pai, principalmente na ausência da explicação, silêncio que se coloca até o final da narrativa, porque não se revela, finalizando-se como uma eterna pergunta sem resposta:

O rumo daquilo me animava, chega que um propósito perguntei: "Pai, o senhor me leva junto, nessa sua canoa?" Ele só retornou o olhar em mim, e me botou a benção, com gesto me mandando para trás. Fiz que vim, mas ainda virei, na grota do mato, para saber. Nosso pai entrou na canoa e desamarrou, pelo remar. $E$ a canoa saiu se indo - a sombra dela por igual, feito um jacaré, comprida longa (ROSA, 2001, p. 80, grifo nosso).

O convite fica no silêncio, e esse nem sim nem não dialoga com o título e toda a narrativa, porque não há escolha, não existe definição. Por outro lado, é essa ausência de resolução que o narrador, de maneira profundamente afetada, faz-nos conhecer pela memória das poucas particularidades psicológicas do pai ausente. O pai sai em sua canoa a partir de uma construção linguístico-literária que, sendo uma comparação, 
nasce de uma metáfora já declarada pelo próprio Guimarães, ao afirmar ter atração pelos rios e remetendo-os ao eterno:

As aventuras não têm tempo, não têm princípio nem fim. E meus livros são aventuras: para mim, são a maior aventura. Escrevendo, descubro sempre um novo pedaço de infinito. Vivo no infinito; o momento não conta. Quando escrevo, repito o que vivi antes... Gostaria de ser um crocodilo porque amo os grandes rios, pois são profundos como a alma do homem. Na superfície são muito vivazes e claros, mas nas profundezas são tranquilos e escuros como os sofrimentos dos homens. Amo ainda mais uma coisa de nossos grandes rios: sua eternidade. Sim, o rio é uma palavra mágica para conjugar eternidade. (LORENZ, 1994, p. 38)

Assim, o conto é a própria dimensão da ambiguidade, na medida em que as possibilidades de interpretação têm como base não a lógica, principalmente no que tange à solução única dos fatos narrados. A dúvida impera ao longo do narrar do nosso protagonista, por exemplo, quando este não apresenta uma certeza em relação à possível refeição realizada pelo pai, conforme os mantimentos são deixados à margem do rio. Não sabemos, portanto, se o pai ou os bichos comem o pouco alimento:

Enxerguei nosso pai, no enfim de uma hora, tão custosa para sobrevir: só assim, ele no ao-longe sentado no fundo da canoa, suspendia no liso do rio. Me viu, não remou para cá, não fez sinal. Mostrei o de comer, depositei num oco de pedra do barranco, a salvo de bicho mexer e a seco de chuva e orvalho. (ROSA, 2001, p. 81)

O sertão ficcional de João Guimarães Rosa não se concretiza na perspectiva da realidade puramente racional; tudo converge para o plano da ausência de resposta, como é possível perceber claramente no caráter de Riobaldo, protagonista de Grande sertão: veredas, obra máxima do autor mineiro. Riobaldo vive em uma eterna dúvida, mote que se coloca em todo o romance: a existência ou não do diabo. De acordo com Coutinho: "Nesse universo, fluido, pantanoso, e marcado justamente pela coexistência de opostos em constante tensão, toda versão única e excludente de algo é desautorizada" (COUTINHO, 2008, p. 365).

Desautoriza-se, pois, qualquer possibilidade de elevar os acontecimentos ao caráter de unicidade, desenvolvendo-se aquilo que Eduardo Coutinho, em Discursos, fronteiras e limites na obra de Guimarães Rosa, chama de "fluidez", um movimento impossível ou incapaz de colocar-se em solução cartesiana, na busca da verdade lógica. Assim, segundo Coutinho, a narrativa coloca "em xeque todo tipo de lógica alternativa, calcada em construções dicotômicas, e, abrindo espaço para outras possibilidades, quica para uma lógica que poderíamos chamar de 'aditiva"” (Ibidem, p. 365). 
Estamos diante da grande dúvida do sujeito moderno, que muitas vezes recorre aos mitos, em busca do atemporal e eterno, na maneira de narrar do século XX da literatura latinoamericana. O homem desse momento histórico não mais compreende a realidade pela razão, já que não existem mais compreensões acertadas, negando-se qualquer valor moral ${ }^{7}$ de construção social como universal. Em "A terceira margem do rio" é impossível um julgamento, inclusive do ponto de vista da decisão do pai, pois não há certeza. Na medida em que o enredo se desenvolve, mais difícil é a tarefa de realizar qualquer juízo ético, caso consideremos a moralidade como uma escolha de más ou boas virtudes. De acordo com Coutinho, em Grande Sertão: veredas. Travessias:

A contestação da lógica dicotômica, alternativa, da tradição cartesiana, em favor da busca de uma pluralidade de caminhos, é uma das tônicas de toda a ficção rosiana e acha-se presente em cada elemento das narrativas do autor, desde os personagens e o espaço até a linguagem utilizada. A obra de Guimarães Rosa é uma obra plural, híbrida, indagadora, marcada pela ambiguidade e pelo signo da busca, que se ergue como uma constelação de elementos muitas vezes opostos e contraditórios. Regional e universal, mimética e consciente de seu próprio caráter de ficcionalidade, "realista" e "antirrealista", ela é, por excelência, um produto do século XX, uma arte de tensões e relatividade e, ao mesmo tempo, a perfeita expressão do contexto de onde emerge, uma terra que só pode ser compreendida quando vista como um amálgama de culturas. (COUTINHO, 2013, p. 32)

A escrita moderna, cujo exemplo aqui dá-se com Guimarães Rosa, carece de explicação lógica em sua tessitura interna, mesmo na perspectiva literária do discurso, da qual o enigma ${ }^{8}$ faz parte como "monumento" metafórico. Dessa forma, estamos falando de questões internas ao texto que convergem na ausência racionalista - imersa em toda a narrativa -, elaboradas sobretudo no silêncio ou na incapacidade física de um sujeito lidar com a intempérie da natureza. Aristóteles argumenta no Órganon a possibilidade de organizar racionalmente o agir individual a partir do coletivo:

É mais fácil definir o particular do que o universal e, portanto, deveríamos proceder dos particulares para os universais. Também é mais difícil detectar ambiguidades nos universais do que nas espécies ínfimas. Tal como a demonstração exige rematada inferência, a definição exige clareza, o que será obtido se pudermos - por meio de traços comuns que estabelecemos - definir nosso conceito separadamente em cada classe de objetos (por exemplo, definir a

\footnotetext{
7 Entendemos o valor moral como escolha, decisão realizada a partir de pressupostos éticos, desenvolvendo-se no indivíduo a partir de constructos morais - na busca da felicidade, como pensara Aristóteles, ou na instrumentalização da racionalidade categórica, como formulara Kant.

8 "A partir de bons enigmas que se constituem geralmente metáforas apropriadas. Ora, metáforas implicam enigmas e, por conseguinte, é evidente que são bons métodos de transposição." (ARISTÓTELES, Retórica, III, II, 1405 b).
} 
similaridade não no geral, mas com respeito às cores ou formatos, e definir o agudo com respeito ao som), e assim avançar à definição geral. (ARISTÓTELES, Órganon, II, XIII, 97 b1 25-30)

Em "A terceira margem do rio" o enredo ultrapassa a lógica em suas diversas possibilidades, já que não é possível iniciar qualquer julgamento em relação ao pai, porque o que temos como aspectos ligados ao personagem são apenas impressões afetivas de um filho abalado com a ida sem razão. A aventura do pai, uma espécie de viés quixotesco em Primeiras estórias, constitui-se no ilógico do ir e ao mesmo tempo não se afastar da margem próxima à casa, como fica evidente no discurso do narrador ao tentar explicar o inexplicável:

Nosso pai não voltou. Ele não tinha ido a nenhuma parte. Só executava a invenção de se permanecer naqueles espaços do rio, de meio a meio, sempre dentro da canoa, para dela não saltar, nunca mais. A estranheza dessa verdade deu para estarrecer de todo a gente. Aquilo que não havia, acontecia. Os parentes, vizinhos e conhecidos nossos, se reuniram, tomaram juntamente conselho. (ROSA, 2001, p. 80 , grifo nosso)

O ilógico é a clave da narrativa: "Aquilo que não havia, acontecia". Assim, tecer um sujeito que carrega traços de uma coletividade, como elabora Aristóteles no Órganon, é praticamente impossível: "Por exemplo, se Alcebíades, Aquiles e Ájax são grandiosos de alma, qual era sua característica comum? Não suportar a desonra, uma vez que foi isso que fez o primeiro ir à guerra, despertou a ira do segundo e levou o terceiro a cometer suicídio" (ARÍSTÓTELES, Órganon, II, XIII, 97 b1 15-20).

Aristóteles, em Ética a Nicômaco, trata de formulações éticas a partir da perspectiva do caráter coletivo dos cidadãos de Atenas, constituindo-se como virtude as ações éticas por excelência. No entanto, o pensador estagirita formula sua ética com base no coletivo, como é citado no Órganon, cuja questão refere-se às ações acertadas ou erradas dos sujeitos no interior dos códigos éticos: "Pelos atos que praticamos em nossas relações com os homens nos tornamos justos ou injustos; pelo que fazemos em presença do perigo e pelo hábito do medo ou da ousadia" (ARISTÓTELES, Ética a Nicômaco, I, I, 1103 b1 10-15).

Assim, não é possível justificar lógica nem eticamente ${ }^{9}$ o comportamento do velho que construíra a canoa, pois não há indícios ao nível de discurso que possam servir para

\footnotetext{
9 “A admiração pelo pai torna o enunciador cada vez menos capaz de ocupar a posição que assumira desde o início e de proceder a qualquer espécie de julgamento sobre o episódio. Uma das coisas que mais o impressiona no caráter paterno é justamente o poder de superação da culpa que lhe foi tantas vezes atribuída por parentes e amigos. Ele permanece no rio apesar de tudo. Isso só faz aumentar a culpa pessoal do enunciador, uma vez que teve coragem de condená-lo por não sentir culpa." (TATIT, 2010, p. 116)
} 
formularmos "pistas" da retirada do personagem para o rio. Além disso, sua permanência na terceira margem alarga-se na mesma atitude da partida, ou seja, no silêncio: "descrevendo que nosso pai nunca se surgia a tomar terra, em ponto nem canto, de dia nem de noite, da forma como cursava o rio, solto solitariamente" (ROSA, 2001, p. 81).

Nesse sentido, quando se lê o conto, produz-se um estranhamento ou desconforto diante do enredo de acordo com os afetos do enunciador, que nos coloca numa narrativa imersa em questões ilógicas e na incapacidade de julgamento acertado do pai. No início, o narrador postula breves comentários de juízo ético, talvez emaranhado no discurso da mãe e esposa aflita: "Cê vai, ocê fique, você nunca volte!” (Ibidem, p. 80); entretanto, qualquer capacidade de juízo perde-se à medida que o tempo passa.

O tempo, então, insere o enunciador no plano da culpa e da dúvida, mas eleva o pai à terceira margem: a possibilidade de manifestações do sublime. O homem eleva-se à margem onde o julgamento ético deixa de ser postulado como capacidade humana, pois o sujeito não mais parece emergir do humano, já que sua força ou projeto caminha para um crescimento moral em detrimento do físico ${ }^{10}$, como pensara Friedrich Schiller em Do Sublime ao Trágico: "Para o sentimento do sublime é absolutamente exigido, portanto, que nos vejamos completamente abandonados de todo meio de resistência físico e que busquemos auxílio, ao contrário, em nosso Eu não físico. Tal objeto tem de ser temível para nossa sensibilidade” (SCHILLER, 2011, p. 30).

Portanto, é possível considerar o emaranhado da dúvida desenvolvendo-se para o estranhamento em face da impossibilidade física de qualquer homem permanecer numa canoa, no alto do rio, sem comida ou vestimenta, como declara o filho: "Mas eu sabia que ele agora virara cabeludo, barbudo, de unhas grandes, mal e magro, ficado preto de sol e dos pelos, com aspecto de bicho, conforme quase nu" (ROSA, 2001, p. 83). O narrador expõe suas impressões em relação a suas incertezas, caminhando para a incapacidade do julgar, porque o grande feito do pai, realizado em silêncio, emaranha-se em uma atividade sobre-humana, isto é, em uma excelsa dedicação, seja qual for o motivo.

A narrativa finaliza sem resolução no que tange à explicação racional ou lógica, pois o pai não volta para a margem primeira ou para a segunda, símbolos da dialética racionalista, ficando na terceira - o único gesto ou expressão não se efetiva, ou é apenas uma ilusão dos

\footnotetext{
10 "Para haver sublime é necessário, portanto haver, por um lado, sofrimento físico, por outro, resistência moral ao sofrimento. Para haver sublime é preciso que à impotência física corresponda a força moral. Como se o homem moral pudesse ser destruído fisicamente, mas não derrotado espiritualmente." (MACHADO, 2006, p. 69)
} 
conflitos internos do filho saudoso, que se habituara a permanecer numa eterna culpa diante do rio. Ao final da narrativa, o filho foge, e essa atitude concretiza a ausência da certeza, restandolhe apenas falhas conjecturas no que tange ao objeto da dúvida. O filho corre, foge e, com ele, a lógica e a dialética racional:

Ele me escutou. Ficou de pé. Manejou remo n'água, proava para cá, concordado. E eu tremi, profundo, de repente: porque, antes, ele tinha levantado o braço e feito um saudar de gesto - o primeiro, depois de tamanhos anos decorridos! E eu não podia... Por favor, arrepiados os cabelos, corri, fugi, me tirei de lá, num procedimento desatinado. (Ibidem, p. 85).

\section{Considerações Finais}

Benedito Nunes, em Guimarães Rosa quase de cor: rememorações filosóficas e literárias, afirma que a possibilidade de ler os textos do autor mineiro dá-se de variadas formas - espécie de método, no qual aplicamos os conceitos filosóficos na leitura de textos literários, sem desmerecimento de um ou outro.

A maneira que achamos conveniente para essa reflexão em torno de "A terceira margem do rio", conto mais emblemático de Primeiras estórias, tem relação com o que Nunes chama de leitura instrumental. Assim, segundo Nunes, "O segundo modo, que chamaríamos de instrumental, utiliza-se, abstraindo a história da filosofia, de conceitos exponenciais, para elucidar as situações e os conflitos dos personagens” (NUNES, 2013, p. 270).

Nossa reflexão, portanto, desenvolve-se na possibilidade de lermos “A terceira margem do rio" a partir de conceitos filosóficos, pautas importantes da filosofia, como a lógica e a ética ocidentais, cuja clave encontra-se na dialética aristotélica.

Em Primeiras estórias podem-se ler os contos à luz das variadas formulações da filosofia que se adaptam ao sertão ficcional de Guimarães Rosa, como explicara Nunes ao mencionar o lugar ficcional como "Sertão-mundo": "Mas quase sempre escalando o Sertãomundo de que não saem. Por isso, nos textos de Rosa, o cômico e o trágico, o reles e o sublime, passam-se a céu aberto" (Ibidem, p. 274-275). 
Referências

ARISTÓTELES. Ética a Nicômaco. In: Os Pensadores. Tradução de Leonel Vallandro e Gerd Bornheim. São Paulo: Editora Abril Cultural, 1984.

. Obras Completas. Coordenação de António Pedro Mesquita. Lisboa: Imprensa Nacional- Casa da Moeda, 2005.

Órganon. Tradução de Edson Bini. São Paulo: Editora Edipro, 2005.

CUNHA, Betina R.R.da. Um tecelão ancestral: Guimarães Rosa e o discurso mítico. Belo Horizonte: Editora ANNABLUME, 2009.

COUTINHO, Eduardo. Discursos, fronteiras e limites na obra de Guimarães Rosa. In: A poética migrante de Guimarães Rosa. Organização de Marlí Fantini. Belo Horizonte: Editora UFMG, 2008, pp. 365-378.

. Grande sertão: veredas. Travessias. São Paulo: É Realizações,

2013.

GOULART, Audemaro Taranto. A insatisfação com a margem do rio. In: Outras margens. Organização de Lélia Pereira Duarte e Maria Theresa Abelha Alves. Belo Horizonte: Editora Autêntica, 2001, pp. 07- 20.

LORENZ. G. Diálogo com Guimarães Rosa. In: ROSA, João Guimarães. Ficção completa. Rio de Janeiro: Nova Aguilar, 1994. V.1. pp- 25-61.

MACHADO, Roberto. O Nascimento do Trágico: De Schiller a Nietzsche. Rio de Janeiro: Jorge Zahar Editor, 2006.

NUNES, Benedito. Guimarães Rosa quase de cor: rememorações filosóficas e literárias. In: A Rosa que é de Rosa: Literatura e Filosofia em Guimarães Rosa. Organização de Victor Sales Pinheiro. Rio de Janeiro: Editora Difel, 2013, pp.267-278.

. O dorso do tigre. São Paulo: Editora 34, 2009.

ROSA, Guimarães. Primeiras Estórias. 15ª edição. Rio de Janeiro: Nova Fronteira, 2001.

SCHILLER, Friedrich. Do Sublime ao trágico. Tradução de Pedro Süssekind e Vladimir Vieira. Belo Horizonte: Autêntica, 2011.

TODOROV, Tzvetan. Introdução à Literatura Fantástica. Tradução de Maria Clara Correa Castello. $4^{\mathrm{a}}$ ed. São Paulo: Editora Perspectiva, 2010.

TATIT, Luiz. Semiótica à luz de Guimarães Rosa. São Paulo: Ateliê Editorial, 2010. 
VALENTE, Luiz Fernando. Mundivivências: leituras comparativas de Guimarães Rosa. Belo Horizonte: Editora UFMA, 2011. 